\title{
Seguritización de la indigeneidad. La actual política indigenista de Argentina y Chile
}

\author{
Securitization of indigeneity. The present of the indigenous policy in \\ Argentina and Chile
}

Miguel Leone miguelleone@hotmail.com

http://orcid.org/0000-0002-1618-6968

Instituto de Estudios de América Latina y el Caribe;

Facultad de Ciencias Sociales; Universidad de Buenos Aires/ Consejo Nacional de Investigaciones Científicas y Técnicas (Argentina)

\section{Resumen}

En Argentina, la llegada de un partido de derecha al gobierno nacional implicó modificaciones pronunciadas en muchas de las dimensiones de la construcción de estatalidad. La política estatal indigenista es un ejemplo de ello. Este artículo sostiene que se está consolidando un modelo de política gubernamental basado en la seguritización de la indigeneidad y que reconoce en el caso chileno su principal referente. Partiendo de esa afirmación, el trabajo analiza los vasos comunicantes entre la administración de los conflictos etno territoriales por parte del Estado chileno durante los últimos años y la actual política estatal indigenista argentina. Se asume que, al compás de mutaciones en las políticas indigenistas de ambos países, la idea de "indígena" está siendo reinventada e inscripta en nuevas estrategias de gubernamentalidad. 
Palabras clave: seguritización; indigeneidad; Chile; Argentina; política indigenista.

\section{Abstract}

The arrival of a right party to the national government in Argentina involved intense modifications in many dimensions of the statality construction. The indigenous policy is an example of this; however, researchers and social analysts are not putting sufficient attention. This article argues that it is consolidating a model of governmental politics based in the securitización of indigeneity. The Chilean case is his main referent. The work analyses the interrelationships between the administration of the ethnics and territorial conflicts by the Chilean state during the last years, and the current indigenous policy in Argentina. It supposes that, with these mutations in the indigenous policy on both countries, the idea of "indigenous people" it is being reinvented and inscribed in new strategies of gubernamentality.

Keywords: securitization; indigeneity; Chile; Argentina; indigenous policy.

Durante las últimas décadas, la existencia de movimientos sociales y formas de organización política indígena impusieron a los Estados latinoamericanos nuevos desafíos políticos. Desde los años sesenta y setenta del siglo $\mathrm{XX}$, estos se encontraron con la urgencia de lidiar con grupos indígenas políticamente activos, estratégicamente orientados -aunque con grados variables de organicidad-, y socialmente legitimados. Ante estos cambios en la política indígena, los Estados se vieron obligados a reordenar estratégicamente sus políticas indigenistas (1).

La política indigenista del Estado argentino se ha caracterizado a lo largo de su historia por poseer un carácter inorgánico, errático y contradictorio (Lenton, 2010). Ella siempre ha sido el efecto de voluntades encontradas, escasamente planificadas y atadas a intereses múltiples y localizados. Aun así, es posible detectar, en los distintos momentos históricos, líneas directrices o generales que pueden ser leídas como el ethos hegemónico de cada período. Durante los años sesenta y hasta principios de los años setenta, el desarrollismo proveyó buena parte de la epistemología y los dispositivos de articulación de políticas estatales indigenistas. Por entonces, la idea de "promoción de las comunidades" y el desarrollo de las "zonas atrasadas" fueron los principales vectores de la tan buscada "integración" del indígena. 
Hacia la década de 1980, en cambio, el multiculturalismo crecientemente avanzó sobre la agenda gubernamental indigenista. Fue el tiempo de legislaciones que reconocieron derechos a la educación bilingüe, primero; intercultural, después; la conformación de "comunidades", la entrega de títulos comunitarios de tierras y la salud intercultural, entre otros derechos (Carrasco, 2000; GELIND, 2000; Leone, 2016). Hacia los años noventa, se observó cierto impulso a la consulta y la participación restringida de pueblos y referentes indígenas en la generación y puesta en funcionamiento de la política estatal indigenista. A partir de la crisis de 2001-2002, esta política estatal adoptó una lógica de "neoindigenismo de necesidad y urgencia" en el que aquella participación indígena fue incrementada, aunque absorbida en estrategias neoliberales de política social focalizada. De esa forma, convertidos en "aplicadores" de tales políticas, los indígenas pasaron a ser responsabilizados por los (magros y siempre insuficientes) efectos alcanzados (Lenton y Lorenzetti, 2005).

Por cierto, el desarrollismo, el multiculturalismo, la juridización, la "participación" y el neoindigenismo -entre otras- son matrices o esquemas de la política estatal indigenista que, en grados variables, resultan reconocibles en la actual dinámica de relacionamiento entre el Estado y los distintos pueblos originarios en la Argentina. Sin embargo, en este artículo quiero plantear que, actualmente, -y en el marco de una (re)militarización de la seguridad pública (Anzelini, 2017)- el sentido hegemónico de la acción estatal indigenista se encuentra en pleno proceso de viraje: desde 2016-2017 se asiste a un nuevo cambio de rumbo de la política estatal indigenista que cada vez más adopta una lógica de seguritización. Sin borrar por completo aquellas líneas pretéritas de relacionamiento Estado-pueblos originarios, un nuevo vector comenzó a instalarse como elemento hegemónico en la política estatal indigenista. El mismo se encuentra marcado por la criminalización de la indigeneidad (de la Cadena y Starn, 2009) y los "problemas" construidos en relación con ella.

\section{Nahuel y Santiago}

El 1 de agosto de 2017, Santiago Andrés Maldonado -joven militante social solidario con la causa mapuche- desapareció en el marco de un violento operativo desplegado por Gendarmería nacional en el Pu Lof (2) Cushamen; un lof que mantiene un largo conflicto con la empresa multinacional Benetton que se adueñó de 900 mil hectáreas en la zona. Durante 81 días, el Estado argentino cometió el delito de desaparición forzada a través del ocultamiento de información, la falta de comunicación pública e, incluso, la divulgación de informaciones falsas 
sobre el hecho. El 17 de octubre, el cuerpo de Santiago apareció sin vida flotando en el río Chubut.

El 25 de noviembre, miembros del Grupo Albatros, un grupo de elite de la Prefectura Naval, asesinaron al activista mapuche Rafael Nahuel en el marco de un operativo de seguridad en Villa Mascardi, 35 kilómetros al sur de la ciudad de Bariloche.

Estos hechos expresan la cristalización de un modelo de política gubernamental indigenista cuyos primeros antecedentes en el caso local remiten, cuanto menos, a la primera década del siglo XXI. En efecto, las muertes de Santiago y Nahuel se inscriben en una línea de asesinatos de miembros de pueblos indígenas y activistas indigenistas que durante los últimos años han venido presentándose con relativa asiduidad en la Argentina.

En el clima de las celebraciones del Bicentenario de la Revolución de Mayo, se registraron varios crímenes contra los pueblos originarios en distintas zonas del país. En general, se trató de asesinatos en el marco de conflictos territoriales generados tras el avance del capital extractivo y los cultivos transgénicos (Hocsman, 2014) (3). Algunas de esas muertes fueron producidas por las fuerzas policiales provinciales o fuerzas denominadas "intermedias", como la Gendarmería nacional. Tales los casos de Roberto López (qom), de la comunidad La Primavera, en Formosa, en 2010 (4) y de cuatro guaraníes (Ariel Farfán, Félix Reyes, Víctor Heredia y Juan Ledesma) a instancias de un desalojo en el Ingenio Ledesma en Jujuy en 2011 (5). Otras muertes fueron generadas por privados y/o sicarios contratados por terratenientes directamente implicados en los conflictos de tierras. Tales los asesinatos de Cristian Ferreyra en Santiago del Estero, en 2012, y del dirigente Javier Chocobar, perteneciente a la comunidad diaguita Chuschagasta, en la provincia de Tucumán, en 2009, en la emblemática fecha del 12 de octubre.

Ahora bien, a diferencia de las muertes de Santiago y Nahuel, los asesinatos anteriores no contaron con el beneplácito explícito de funcionarios de alto rango del Poder Ejecutivo nacional. Tampoco respondieron a un programa de política estatal indigenista ideado a nivel nacional (6). Allí radica la novedad de los casos de Santiago y Nahuel, la cual merece ser especialmente atendida.

En efecto, el operativo en el que Santiago desapareció fue realizado bajo la mirada atenta del Jefe de Gabinete del Ministerio de Seguridad de la Nación, Pablo Nocetti; y en ambos casos las fuerzas implicadas en los crímenes contaron con el apoyo y complicidad de la Ministra de Seguridad, Patricia Bullrich. Además, es pertinente observar que la muerte de Santiago se produjo al día siguiente de una reunión que Nocetti mantuvo en Bariloche con responsables de las carteras de seguridad de Chubut, Neuquén y Rio Negro (las tres provincias con mayor 
porcentaje de población mapuche). El objetivo de dicha reunión había sido, precisamente, establecer lineamientos conjuntos para acabar con el "terrorismo" de grupos mapuche violentos; una terminología que concuerda con las afirmaciones que la ministra hiciera luego de ambas muertes: defendiendo enfáticamente el accionar de las fuerzas de seguridad, postuló, sin ninguna prueba fehaciente, la condición de "terroristas" de los activistas asesinados.

Sería un error interpretar tales declaraciones a partir de la sinrazón de un funcionario público que acumula -por cierto- una serie numerosa de afirmaciones con dudoso sentido de realidad. En cambio, es pertinente entenderlas como una práctica discursiva orientada a transformar la política estatal indigenista. En el gobierno de Cambiemos, la política indigenista está pasando a ser inserida en esquemas que entienden la protesta social y política como "peligros a la seguridad nacional" y/o "amenazas al orden social". Tales miradas se inscriben, a su vez, en una reorganización hegemónica a nivel global (Calveiro, 2012) caracterizadas por la seguritización de la vida gobernable y la expansión de la figura de Estado de excepción (Agambem, 2005); dispositivo biopolítico propio de nuestras sociedades modernas. Pues, gracias a ello son creadas "las condiciones jurídicas para que el poder disponga de los ciudadanos en tanto vidas desnudas" (Agambem, 2005: 6).

El concepto de seguritización remite a la dinámica gubernamental por la cual una diversidad de temas (políticos, sociales, económicas, etcétera) pasan a ser tratados bajo la óptica de la "seguridad" (7). El esquema de política estatal indigenista que está en pleno proceso de construcción en la Argentina hace de la seguritización de la indigeneidad su principal eje de acción. Se trata de un proceso por el cual la protesta social etno-territorial es criminalizada y leída en clave de problema de seguridad; los activistas estigmatizados como terroristas y, consecuentemente, perseguidos a través de los dispositivos del derecho penal. Al momento, este esquema está siendo aplicado, fundamentalmente, sobre los pueblos mapuche y wichi. Con ello, se observa que los Ministerios de Desarrollo Social, Educación y/o Salud pierden cada vez más el protagonismo en la definición de la política indigenista, al tiempo que cede ese lugar al Ministerio de Seguridad. Es decir, en el esquema de política estatal indigenista, paulatinamente cobra mayor lugar -y financiamiento- la política represiva, de inteligencia y vigilancia sobre las comunidades y pueblos originarios, en detrimento de las políticas de salud, educación intercultural y/o reconocimiento territorial y propiedad comunitaria de tierras.

El actual proyecto argentino de política indigenista encontró en el modelo chileno una vía para su sistematización y un horizonte de realización. En efecto, Chile presenta uno de los más claros ejemplos de seguritización de la indigeneidad. Y si bien en la Argentina, durante la última década y media, los conflictos etno-territoriales estuvieron siendo gestionados de modos 
diversos y muchas veces contradictorios, en la actualidad se observa un viraje cada más acentuado hacia formas de gestión emparentadas con las lógicas observadas en el vecino país cordillerano. Siendo así, será pertinente echar una mirada sobre el caso chileno para poder iluminar con mejores herramientas el caso local. Tener presente los principales modos de administración de los conflictos etnoterritoriales en Chile permitirá encontrar mejores interrogantes desde donde entender el presente -y probablemente también prevenir el futurode la política estatal indigenista argentina. A continuación, y atendiendo a los fines de este trabajo, se propone una mirada sobre el momento en que la seguritización de la indigeneidad se instaló en Chile como modelo de gestión de la indigeneidad (1999-2003).

\section{Chile}

El golpe de Estado a Salvador Allende abrió un proceso de reversión de muchas de las recuperaciones territoriales que el pueblo mapuche había conseguido al compás de los procesos de reforma agraria. También implicó, hacia los años ochenta, el avance de las empresas forestales en la décima y novena región, esto es, los territorios tradicionales de ese pueblo originario. Con ello, los mapuche no sólo fueron víctimas de la pérdida de derechos territoriales, sino también de una profunda alteración en el plano de su cosmovisión cultural: en nombre de la mayor eficiencia en el cultivo de eucaliptus, las empresas forestales optaron por hacer cambios artificiales de los cursos de los ríos y contaminaron sus aguas; produciendo una pronunciada desertificación del territorio y la migración de variedad aves y animales del monte. Por su parte, el alto nivel de tecnificación de la actividad forestal impidió que la empobrecida población mapuche contrarrestara estas pérdidas -si acaso existe una forma de contrarrestarlas- con oportunidades de trabajo en el "desarrollo" económico impuesto por las empresas forestales. Así, como lúcidamente señala Fernando Pairican (8), durante la larga década en que crecieron los eucaliptus de las forestales, también nacieron y se formaron políticamente los jóvenes mapuche que, hacia finales de los años noventa, impulsaron un nuevo ciclo de movilización.

José Marimán (1994) sostiene que "la organización étnico-gremial mapuche-campesina" se caracteriza por emerger según "ciclos de movilización" y ante problemáticas puntuales de cada coyuntura. En sus palabras, un ciclo de movilización mapuche "es un período en que la iniciativa en el enfrentamiento o en la negociación con el Estado está en manos del movimiento mapuche, gracias, precisamente, a su capacidad de movilización" (Mariman, 1994: 99). En 
Chile, hacia 1997 se inauguró, efectivamente, un nuevo ciclo de movilización mapuche. Ese año, la Coordinadora de Comunidades en Conflicto Arauco Malleco (CAM) (9) se auto-inculpó por la quema de camiones de una empresa forestal en la zona de Lumaco, provincia de Malleco (al norte de Temuco). La CAM declaró entonces estar en "guerra" contra el Estado capitalista y a las empresas amparadas y protegidas por él. Desde ese momento, los conflictos tomaron nuevos carices, y ganaron terreno posturas en favor de que la violencia estatal y capitalista fuera contrarrestada y frenada a través de la violencia política de los weichafe (guerrero) mapuche.

El estado chileno respondió a esta nueva dinámica del movimiento mapuche con políticas represivas y programas policiales y militares de desarticulación del movimiento. Un primer antecedente de la política represiva hacia el movimiento indígena en el Chile pos-dictadura puede registrarse en marzo de 1992, cuando el Consejo de Todas las Tierras (CTT) emprendió lo que se denominó como "recuperaciones simbólicas" (10) de territorio. El gobierno reprimió y apresó a cientos de comuneros, acusándolos -en juicios viciados de irregularidades- de "usurpación de propiedad" y "asociación ilícita". Pero, independientemente de aquel antecedente, lo cierto es que recién hacia 1998-2000 esta lógica represiva comenzó a ganar centralidad en la agenda indigenista que el Estado dirigió hacia el pueblo mapuche.

En julio de 1999 el Centro de Estudios e Investigaciones Militares (CESIM) afirmaba que el "conflicto mapuche" representaba un problema de relevancia militar; que podría transformarse en "un conflicto perturbador en el país [y] que podría poner en riesgo la seguridad nacional" (11). Al mismo tiempo, en un artículo firmado por la Capitán Paula Videla del Real, las lógicas de solidaridad entre organizaciones sociales defensoras de los derechos de los pueblos eran tergiversadas y leídas como amenazas a la seguridad interior y desafíos a la soberanía:

en la búsqueda de sus objetivos reivindicacionistas, las comunidades mapuches han encontrado respaldo en organizaciones nacionales e internacionales de protección a las minorías, a través de las cuales han recibido apoyo y orientación. Estas influencias, que han trasplantado a la situación chilena elementos socioculturales foráneos, sólo han contribuido a distorsionar la verdadera realidad de las comunidades indígenas en nuestro país (12).

El artículo planteaba que el "conflicto indígena" "afecta el orden interno y la tranquilidad pública del país" y vulnera el derecho de propiedad consagrado por la Constitución. En virtud de ello, Ilamaba a aplicar la Ley de Seguridad del Estado, "a través de la cual se procura la preservación del orden jurídico institucional del país" (13). 
Siendo éste el espíritu imperante en el ámbito militar, desde entonces la política gubernamental indigenista crecientemente se nutrió de esas cosmovisiones y diagnósticos.

Por su parte, hacia finales de 2001 la CAM multiplicó las acciones de protesta, incendiando las plantaciones forestales de las empresas Arauco y Mininco. El Estado chileno encontró allí motivos suficientes para intensificar el despliegue de fuerzas represivas en diferentes zonas juzgadas "conflictivas". Los carabineros pasaron a operar en el interior de los fundos forestales, en donde fueron creados campamentos móviles y fijos con efectivos policiales en permanente rotación. Al mismo tiempo, se habilitó que guardias privados, autoproclamados como miembros del Comité de Defensa de los Predios (14) efectuaran patrullajes en el espacio rural.

Las sugerencias que en 1999 hiciera el CESIM se concretaron como política de Estado a partir de la llegada a la presidencia de Ricardo Lagos (2000-2006) (15). Entonces, la lógica represiva se instaló en forma sistemática como lógica de administración de los conflictos etno-territoriales (González, Mella y Lillo, 2007). Según se supo unos años más tarde (16), en el año 2000 la Dirección de Inteligencia de la Policía de Carabineros de Chile (DIPOLCAR) dio impulso a la llamada "Operación Paciencia" (OP), la cual se destinó específicamente a desarticular la Coordinadora Arauco Malleco, ya fuera a través de mecanismos legales como ilegales (17). En ese marco, las regiones de Bio Bio y Araucanía -es decir, aquellas directamente afectadas por estas formas de conflictividad etno-territorial- fueron unificadas en la planificación geoestratégica de Carabineros y puestas bajo la dirección del General José Alejandro Bernales. La OP contó con el apoyo del Grupo de Operaciones Policiales Especiales (GOPE) e implicó la militarización del Wallmapu. Se implementaron controles de carabineros en las comunidades y los caminos rurales y se crearon Juntas Rurales Vecinales, capacitadas por las propias fuerzas de seguridad y equipadas, inclusive, con radios de frecuencia (Figueroa Cerda, s/f). Paralelamente, la infiltración de falsos militantes mapuche y la falsificación de pruebas también fueron parte fundamental de esta estrategia represiva.

Desde entonces, la presencia de carabineros en las comunidades da lugar a escenarios de provocación selectiva, personal, íntima, que los agentes de fuerzas de seguridad hacen sobre los comuneros. Ya a mediados de 1999, un memorando de un general de carabineros (jefe de la IX Zona de la Araucanía) señalaba:

Se puede apreciar con absoluta claridad que el personal de Carabineros llega al lugar de los hechos con un ánimo confrontacional predispuesto, e incluso en más de algún procedimiento ha sido la actuación policial desmedida y prepotente la que ha provocado la reacción de los mapuche (Toledo Llancaqueo, 2007: 263). 
Pero no se trata de simples "actuaciones desmedidas y prepotentes", circunstanciales, fortuitas, surgidas en "más de algún procedimiento". Se trata en cambio, de una lógica de funcionamiento de la política represiva que se fundamenta en la producción, por parte de las propias fuerzas de seguridad, de las condiciones necesarias para la generación del hecho reprimible y judicializable. Toda una técnica estatal de construcción del conflicto. Para ser más explícitos: las detenciones en la vía pública, el maltrato físico y psicológico, los insultos racistas que los agentes de seguridad propinan a los ciudadanos indígenas no son meros actos de abuso de poder efectuados por un agente de seguridad que se desborda de sus responsabilidades oficiales. Por el contrario, ellas son parte de una estrategia orientada a producir el conflicto en terreno; promoviendo comportamientos reactivos de los indígenas que funcionan luego como justificación para la intervención de medidas punitivas y judiciales, la criminalización de los sujetos indígenas y la estigmatización de su comunidad.

Antes que una simple o mecánica traducción de las teorías jurídicas, las prácticas penales siempre son parte de una específica anatomía política del ejercicio del poder (Foucault, 2002). En este sentido, y atendiendo al uso poco legalista que el Estado hace en la aplicación del derecho penal sobre el pueblo mapuche, es posible pensar que la producción del conflicto en terreno se orienta a construir al indígena como enemigo para habilitar formas diversas de suspensión de la norma (Agamben, 2005).

En 2001 y 2002, el "conflicto mapuche" cada vez más pasó a ser leído -por parte del Estadocomo una "amenaza terrorista" y, por tanto, un problema de orden público y seguridad. En términos del Centro de Estudios e Investigaciones Militares (CESIM), una "verdadera amenaza global que traspasa las fronteras con facilidad, dejando obsoletos numerosos conceptos de seguridad nacional" (18). De allí en más, una amplia y difusa referencialidad y un juego de aproximaciones y rechazos pasaron a articularse en torno de los términos mapuche y terrorista. De forma tal que la marcación de otredad mapuche fundada en los habituales diacríticos culturales (v.g. el trarilonco, el küpam o las rogativas) y lingüísticos (el mapudungun), pasó a apoyarse sobre una confusa apelación al "elemento terrorista" que sería propio de esa "minoría étnica radicalizada".

Los medios de comunicación masiva, los think tank de derecha e incluso no pocos intelectuales han sido actores clave de este trabajo de producción sinonímica. Ellos han creado discursos dirigidos a deslegitimar las reivindicaciones de tierras y los derechos indígenas estatuidos, y enmarcar la cuestión mapuche en la agenda de seguridad. En efecto, cuando en 2000 y 2001 la CAM coordinó un número significativo de acciones orientadas a interrumpir los trabajos de las empresas forestales, hidroeléctricas y mineras en los territorios mapuches, sectores de la 
derecha chilena y la prensa hegemónica denominaron a ese fenómeno como "la Intifada Mapuche". En ese sentido, en las páginas de los diarios, se volvieron frecuentes las imágenes de encapuchados "mapuches beligerantes" portando palos u otras elementales herramientas de defensa y protección.

En línea con estas estrategias discursivas, las leyes de Seguridad Interior del Estado (Nro. 12927) y de Conductas Terroristas (Nro. 18314/84) pasaron a ser aplicadas en forma sistemática por el gobierno como forma de administrar esos conflictos etno-territoriales. De allí en más, la prisión preventiva se convirtió en la figura jurídica que, por excelencia, permitió al gobierno neutralizar la acción militante de los principales líderes, encarcelándolos por largos e indeterminados períodos sin sentencia alguna ni pruebas suficientes. Toledo Llancaqueo (2007: 263-264) ha planteado que, desde 2001 en adelante:

\footnotetext{
Los noveles fiscales, adoctrinados en una nueva dogmática penal, se involucraron de lleno en un espeso conflicto social con el Código Penal en la mano. Su desempeño estaba bajo escrutinio, medido con indicadores cuantitativos, y a sus ojos los actos de protesta mapuche eran decenas de delitos: usurpación, desórdenes, daños, hurto, robo, incendio, asociación ilícita delictiva, etc. En 2001 aumentaron exponencialmente los procesos penales relacionados con la protesta mapuche, con su secuela de allanamientos, detenciones y juicios. (...) La intensa campaña de criminalización se exacerbó hacia 2001 2002, presentando a los mapuches como violentos a quienes se les debía aplicar la ley antiterrorista.

Por su parte, durante todo el año 2002 las comunidades mapuche (Temulemu, Didaico, Aylla Varela, entre otras) fueron objeto de violentos y masivos allanamientos con vehículos blindados y ostentosas demostraciones del poder policial y militar. Muchos de esos allanamientos fueron estratégicamente realizados en horas de la madrugada, de forma de encontrar desprevenidos a los comuneros y procurando generar destrozos en las casas, como forma de amedrentar a las familias mapuche (Figueroa Cerda, s/f).
}

Hay que tener presente que, aunque la propia CAM en sus comunicados hable de "guerra contra el capital" o "guerra contra el Estado", etcétera. sus actos, no dejan de ser formas de protesta social. Ellos no ponen -y jamás pusieron- en peligro el orden público ni pretenden generar terror en la sociedad civil. Tampoco se inscriben en estrategias de toma del poder ni aspiran a derrocar los gobiernos de turno. En definitiva, los actos de reivindicación y reclamo llevados a cabo por distintos sectores del movimiento indígena en el país -incluidos allí los emprendidos, organizados y reivindicados por la CAM- no son actos terroristas. Tampoco son 
actos de guerra, golpistas o guerrilleros. Son, en cambio, actos de protesta que apelan, en grados variables, a un uso estratégico de violencia política.

El 7 de noviembre de 2002, Edmundo Alex Lemun Saavedra fue asesinado en el marco de un desalojo de manifestantes mapuche que ejercía un "control territorial" (ocupación pacífica) en el fundo Santa Alicia de la empresa forestal Mininco (19). Este hecho implicó un importante hito en el proceso de construcción de este modelo de seguritización de la política indigenista. No tanto porque haya habido una muerte a manos de las fuerzas de seguridad del Estado -lo cual ya es por demás grave-, sino antes bien en virtud de la forma en que el gobierno asumió y enmarcó el acontecimiento. Lejos de comprometerse en el enjuiciamiento de los responsables del asesinato, el gobierno optó por una política de impunidad sobre los responsables y una ofensiva aún mayor sobre el movimiento mapuche (la cual, en poco tiempo y a despecho de los cambios de gobierno -y de signo político-, dio lugar a otras nuevas muertes) (20): la Dirección de Seguridad Pública e Informaciones (DISPI) (conducida por Gustavo Villalobos) pasó a entender a la CAM como una organización "insurreccional" que buscaba "incentivar un alzamiento indígena" (21). Cuando apenas se cumplía un mes del asesinato de Alex Lemun, el Ministerio Público de la Araucanía impulsó un proceso judicial en el que acusó a la Coordinadora Arauco-Malleco de "Asociación llícita Terrorista" y propulsó la realización de un vasto operativo dirigido a apresar a muchos miembros y dirigentes de la CAM.

A comienzos de 2003, más de treinta referentes mapuche estaban presos en distintas cárceles regionales. En este contexto, la CAM se vio obligada a pasar a la clandestinidad. Gracias a ello, consiguió continuar existiendo como organización, aunque al costo de ver recortado su trabajo militante en las bases y su contacto con grupos más amplios de la sociedad civil. De todos modos, los asesinatos de mapuche a manos de Carabineros y respaldados por el gobierno, los encarcelamientos de militantes y la persecución política sobre la CAM continuaron produciéndose. Entre finales de 2006 y principios de 2007, fueron apresados José Llanquileo, Héctor Llaitul y José Huenchunao, dirigentes históricos de la CAM. Asimismo, el 3 de enero de 2008, mientras se realizaba una recuperación territorial, las Fuerzas Especiales de Carabineros asesinaron a Matías Catrileo en el fundo Santa Margarita. El 12 de agosto de 2009, durante el gobierno de Michel Bachelet, las mismas fuerzas asesinaron a Jaime Facundo Mendoza Collio.

\section{Argentina}


Actualmente, en la Argentina hay dos espacios geográfico-provinciales en los que la seguritización de la indigeneidad está echando raíces: Formosa-Chaco y Neuquén-Río NegroChubut. Un claro caso en este sentido es el encarcelamiento del militante wichi Agustín Santillán. El mismo pasó la mayor parte de 2017 privado de su libertad por causas carentes de los más elementales instrumentos probatorios; al tiempo que las comunidades de la provincia de Formosa están siendo víctimas de hostigamientos constantes por parte de las fuerzas de seguridad. Según un informe de APDH, existe en el oeste de la provincia de Formosa una "modalidad de persecución" por parte del poder judicial y las fuerzas de seguridad, el cual "tiene como corolario la construcción de un enemigo" (21). Según el mismo informe, el tratamiento que el organismo judicial ha hecho en el caso Santillán muestra "un cercenamiento al debido proceso y a las normas básicas de los tratados de derechos humanos". El informe a su vez denunció un hostigamiento sobre más de cincuenta miembros de la comunidad (entre ellos, la esposa de Santillán):

[se] inculpa a personas que no están vinculadas directamente en los hechos denunciados, librando orden de captura, colocando en situación de indefensión a decenas de ellos puesto que no cuentan con asesoramiento letrado y no están pudiendo ir a trabajar por temor a ser detenidos (22).

El comienzo del 2018 mostró en la comunidad wichi de Barrio Obrero de Ingeniero Juárez (provincia de Formosa), un caso de hostigamiento policial que recuerda la manera en que Carabineros produce la conflictividad in situ en las comunidades mapuche: el 1 de enero, tres wichi menores de edad (entre ellos, dos niños de 11 y 12 años) fueron heridos con balas de goma y de plomo por parte de oficiales de gendarmería destinados a tareas de control y vigilancia de la comunidad (23). Según relataron varios testigos, los gendarmes hostigaron a los niños con expresiones racistas y, cuando éstos respondieron lanzando piedras, aquellos comenzaron a dispararles.

También en este caso los medios de comunicación se convirtieron en parte central del asunto. Ellos establecen apoyaturas múltiples sobre las representaciones que los dispositivos estatales construyen en torno del "indígena conflictivo":

La forma en que los medios se refieren a los hechos en cuestión, dista mucho de favorecer una lectura que atienda a la complejidad de los acontecimientos y a todos los actores involucrados. Preocupa la utilización de términos o vocablos que estigmatizan o profundizan el racismo, por ejemplo, solamente usan la palabra vecino para referirse a los pobladores 
criollos; sobreabundan las referencias a "combate", "vandalismo", "guerra" y refieren el problema de la droga solamente en relación a los jóvenes Wichí" (24).

Aun así, la lógica de construcción estatal de una supuesta "nueva amenaza" indígena a la seguridad parece haber encontrado un terreno más fructífero entre las reclamaciones del pueblo mapuche. En efecto, si la política indigenista nacional comenzó a asemejarse cada vez más a la política indigenista que el Estado chileno ha venido mostrando desde 1999 en adelante, ello resulta particularmente cierto en el espacio geográfico de Chubut-Neuquén-Río Negro. No son pocos los especialistas que advierten sobre la voluntad gubernamental de desplegar el uso de la Ley Antiterrorista en la Patagonia y "reintroducir a las Fuerzas Armadas y a las fuerzas de seguridad en la represión del conflicto social" (25).

En septiembre de 2016 el gobierno anunciaba, en voz del entonces Secretario de Seguridad de la Nación, Eugenio Burzaco que habría sido detectado un "grupo de argentinos [que] se formaron en la organización terrorista Estado Islámico". No obstante, en la misma comunicación, el Secretario reconocía su incapacidad para confirmar cualquier información respecto de la presencia de Isis en el país y -nuevamente- no aportaba evidencia alguna (26). Unos meses después, al comenzar el año 2017, el avance de los desalojos sobre las comunidades mapuche de Neuquén, Chubut y Rio Negro dio lugar a acciones de protesta que los periódicos no tardaron en asignarles supuestas vinculaciones con ETA o ISIS.

Resulta bastante evidente que está en pleno desarrollo una política gubernamental que cada vez más se vuelca hacia una construcción ideológico-discursiva sobre un supuesto "peligro" indígena. La misma resulta funcional a objetivos político-policiales de control social a través de la militarización de las relaciones sociales (Ceceña, 2006). En esa lógica se inscriben las palabras que la Ministra de Seguridad de Argentina pronunció en conferencia de prensa poco después del asesinato de Rafael Nahuel:

En el sur de nuestro país han ocurrido, durante los últimos años, más de setenta acciones violentas o atentados que nos llevan a nosotros a caracterizar que estamos en una situación frente a grupos violentos que han escalado esta situación de violencia. Grupos que no respetan la Ley, que no reconocen a la Argentina, que no aceptan el Estado, la Constitución, los símbolos. Es decir, que se consideran como un poder fáctico que puede resolver con una ley distinta a la ley de todos los argentinos. Esta situación nos lleva a distinguir con absoluta claridad entre los Pueblos Originarios que han resuelto hace muchos años una manera de resolver los problemas que existen, de tierras, de reivindicaciones; de 
estos grupos que no tienen reivindicaciones ni son grupos de protesta, sino que son grupos que han tomado a la violencia como la forma de acción política (27).

En los últimos meses, la RAM ha pasado a ser reconocida por el gobierno argentino como una organización "peligrosa", asociada a la Coordinadora Arauco Malleco, de Chile (28). Sin embargo, ningún funcionario gubernamental ha podido establecer cuántas personas son miembros de la Resistencia Ancestral Mapuche y, hasta el momento, los allanamientos hechos en las viviendas de sus supuestos miembros no han conseguido secuestrar más que moto sierras, hachas, cuchillos y demás herramientas propias del trabajo rural. Como observó Daniel Satur: "Cuando se secuestran panfletos y armas, no se puede demostrar qué sujetos los portaban. Cuando se detiene a sujetos, están desarmados y niegan ser de la RAM" (29).

El 29 de septiembre de 2017, el Subsecretario del Interior de Chile, Mahmud Aleuy, viajó a Buenos Aires para reunirse con Bullrich. Lo hizo con el argumento de que el gobierno argentino tendría información relevante sobre tráfico de armas en la región de La Araucanía. Sin embargo, la visita respondió a razones políticas de más largo alcance. Parte central de la agenda de viaje fue compartir con el gobierno argentino las técnicas de tratamiento del "conflicto mapuche" que las autoridades gubernamentales chilenas llevan a cabo.

El viaje también dio por resultado el compromiso de coordinar acciones conjuntas entre ambos gobiernos. Según declaró el propio Aleuy en conferencia de prensa en el Palacio de la Moneda, el viaje buscaba concretar "un acuerdo previo que tenemos con Argentina [orientado al objetivo] de destruir en conjunto los pasos no habilitados fronterizos que hay en particular en la novena y décima región y un eventual tráfico de armas entre ambos países" (30). Es así que, como resultado del encuentro, fue firmado un acuerdo orientado a controlar supuestos "terrorismos y narcotráficos" por parte de integrantes del pueblo mapuche a ambos lados de la frontera (31). Se concertó ejecutar, en forma inmediata, a partir del mes de octubre de ese mismo año,

un plan conjunto de cierres de pasos fronterizos no habilitados en la región de la Araucanía y activar el sistema para la cooperación en materia judicial respecto de antecedentes vinculados a hechos delictivos en territorios de ambos países (32), para lo cual se utilizarán los convenios de colaboración vigentes entre policías y a nivel de Ministerio Público (33).

Así, el acuerdo no sólo representa una cristalización burocrática e institucional del proceso de adopción del modelo indigenista chileno. El mismo avanza un paso más allá, estableciendo una articulación interestatal de ambos modelos seguritarios indigenistas. Al respecto, establece 
nuevos dispositivos de vigilancia en doce pasos fronterizos -todos ellos localizados en la zona de actual territorialización del pueblo mapuche- y busca construir un cerco policial-militar trasnacional que restringe las libertades no sólo de los mapuche, sino de todos los ciudadanos chilenos y argentinos, independientemente de su pertenencia étnica. Ello lo hace a costa de violar tratados internacionales que ambos países han suscripto (v.g. el Convenio 169 de la Organización Internacional del Trabajo (34), la Declaración de Naciones Unidas sobre los Derechos de los Pueblos Indígenas (35) y la Declaración Americana sobre los Derechos de los Pueblos Indígenas de la Organización de Estados Americanos OEA).

No está de más remarcar cómo las políticas de gobiernos de signos ideológicos supuestamente contrarios como los de Mauricio Macri y Michelle Bachelet consiguieron confluir cuando se trató de asuntos catalogados como de "seguridad interior" y "terrorismo" (36). Aun así, la Ministra de Seguridad argentina advirtió que la articulación interestatal sería fortalecida a partir del 11 de marzo de 2018, cuando llegase a la Moneda el presidente de derecha, Sebastián Piñera (37). En efecto, en el encuentro privado que Macri y Piñera mantuvieron a instancias de la asunción de este último, los pasos fronterizos fueron uno de los temas abordados (38).

En el plano interno, en diciembre de 2017 se reunieron autoridades de las dependencias de seguridad de Chubut, Rio Negro, Neuquén y Nación, dando continuidad al encuentro mantenido en Bariloche en julio del mismo año (ver supra). Esta vez, fue la propia Ministra de Seguridad quien encabezó el encuentro. El mismo planteó la conformación de un "comando unificado" orientado a "perseguir los movimientos de violencia extrema". El informe sobre el cual se fundó tal proyecto planteó la necesidad de que el comando fuese formado por fuerzas de seguridad nacionales e interprovinciales con el objetivo de multiplicar el despliegue de efectivos policiales en las regiones "afectadas" por la presencia de este "peligroso enemigo" mapuche.

Respondiendo a una lógica propagandística antes que técnica, burocrática y políticamente responsable, el Ministerio titulo el informe con el simple nombre de "RAM". El mismo ha cosechado férreas críticas. Pero no tanto por la simpleza y vaguedad de su título, sino, sobre todo, por cuanto en él "se manipulan hechos, se retuercen explicaciones y hasta se cae en lisas y llanas mentiras" (39). Tal como denunció el Espacio Nacional por la Paz y el Dialogo Intercultural, el informe

está plagado de inexactitudes, información intencionalmente distorsionada y sesgado de modo tal, que lleve a la justificación del uso de la violencia estatal. Afirma sin más - 
careciendo del respaldo necesario, dada la gravedad de la información que transmite- que la tal RAM sería un movimiento etnonacionalista violento estrechamente vinculado a la Coordinara Arauco Malleco de Chile (CAM) y dependiente del Movimiento Autónomo del Puel Mapu (MAP), quienes compartirían sus objetivos políticos: la lucha insurreccional contra el Estado argentino (y el Estado chileno) y la propiedad privada de la tierra. (...) todo el material probatorio que presenta este "informe" ha sido tomado de publicaciones en medios masivos de comunicación y de páginas de internet, y en donde se afirma que cuenta con "indicios" propios que probarían la culpabilidad de las organizaciones, dichos indicios no se explicitan". (...) muchos de los hechos denunciados ya han sido públicamente desmentidos (40).

Finalmente, el informe también hace acusaciones sobre una supuesta complicidad de organizaciones de DDHH -como el Observatorio de Derechos Humanos de los Pueblos Indígenas (ODHPI) - con los mapuche "armados" y "violentos". Como puede verse, se trata de la misma estructura discursiva que el CESIM sostenía en Chile hacia 1999: Ios lazos de solidaridad gestados entre organizaciones de la sociedad civil son denunciados como mecanismos de asociación ilegal y amenazas al orden y la seguridad.

\section{Razones de Estado}

Tal como sucede en Chile, la falsedad de la información no es óbice para la construcción de realidad política sobre el tema. Muchas veces, la enunciación de un problema contribuye a construirlo como tal, independientemente de la veracidad de las argumentaciones. Ello resulta especialmente cierto cuando es la voz del Estado quien lo enuncia (Bourdieu, 1993) y, más aún, cuando se encuentra reproducido y replicado en medios masivos de comunicación. Una vez construido el problema pueden activarse los resortes políticos y/o represivos con los que "solucionarlo". Veamos, para finalizar, cuáles son algunos de los principales ladrillos de esa construcción.

En el caso chileno, llama especialmente la atención el nivel de irracionalidad jurídica en la que se sustentan muchos de los procesos judiciales aplicados sobre los miembros del pueblo mapuche. Por un lado, los actos por los que los militantes mapuche son acusados de terroristas remiten a daños sobre bienes materiales (v.g. quema de camiones y/o plantaciones forestales, ocupación de predios, etcétera), lo cual contraviene la doctrina penal e internacional sobre la materia, puesto que no existen los delitos de desprecio de la vida humana o puesta en 
peligro del orden constitucional, dos de los elementos esenciales del crimen de terrorismo. Por otro lado, son recurrentes los casos de fallos absolutorios que acaban siendo anulados por la Corte Suprema para dar lugar a nuevos juicios, violando así el principio de non bis in ídem por el cual ninguna persona puede ser sancionada dos veces por la misma infracción, ni un mismo hecho ser objeto de dos procesos distintos. Asimismo, a pesar de haber sido foco de serios cuestionamientos por parte de Human Rights Watch y la Comisión Interamericana de Derechos Humanos, actualmente la Ley de Conductas Terroristas y la Ley de Seguridad Interior continúan siendo aplicadas de forma sostenida por el Estado chileno sobre los militantes indígenas (Mella Seguel, 2007) (41).

La apelación a la ley antiterrorista en la construcción de las causas responde a que de esa forma el Poder Judicial dispone de mecanismos extraordinarios en el tratamiento dado a los acusados: dicha ley habilita a que la declaración de testigos protegidos o "sin rostro" funcione como prueba inculpatoria; además, permite privar al acusado de su derecho a conocer los motivos de su inculpación (42); suspende las garantías procesales y habilita prisiones preventivas o por sentencia firme- mucho más prolongadas que las contempladas en resto de la legislación penal. Incluso funcionarios estatales y miembros del poder judicial han manifestado públicamente -y sin mostrar la más mínima dosis de vergüenza- su acuerdo con que el sistema funcione así (43).

Al compás de eso, resulta pertinente considerar que, como señala el jurista argentino Antonio Cortina (Mella Seguel, 2007: 193), muchas veces se trata de causas en las que el denunciante es absolutamente consciente de la inconsistencia de las pruebas y la falsedad de la acusación $y$, sin embargo, la emprende como un mecanismo de sujeción del otro-acusado. En su sumatoria y acumulación, las denuncias poco sustentadas consiguen estructurar una red persecutoria en la cual los militantes acaban atrapados, teniendo que ocupar su tiempo vital en la defensa ante el sistema judicial.

\footnotetext{
[Actualmente] el verdadero peligro de los procesos penales no está en la condena sino en el proceso mismo, que significa toda una serie de restricciones y amenazas encubiertas o silenciosas. Las causas se activan, se desactivan, no mantienen un ritmo constante (...) [Se trata de causas que] tienen una peligrosidad y potencialidad represiva constante, y por eso mismo se las instala (En Marcha, abril 2003, año VI, no 31, citado en Mella Seguel, 2007: 193).
}

Finalmente, también importa observar que leyes cómo las de Seguridad Interior y antiterrorista no sólo proveen "ventajas procesales" y habilitan técnicas de persecución judicial sobre los 
militantes. Dichas leyes otorgan al Estado el derecho de controlar por la fuerza territorios y circulaciones, militarizar y ejercer el gobierno bajo el principio de Estado de excepción. Este es un elemento de primer orden en el que asienta el modelo de seguritización de la indigeneidad. Las legislaciones antiterroristas que en la actualidad invaden las arquitecturas legislativas de los distintos estados se fundamentan, tal como lúcidamente lo analizó Pilar Calveiro, en la habilitación de esos espacios de excepción en el ejercicio del poder y la fuerza; en el laberinto biopolítico del hacer vivir y dejar morir; y hacer morir y dejar vivir. En efecto, Terrorismo es, en principio, un método de combate. Pero lo que caracteriza a las llamadas "guerras híbridas" (post mundo bipolar) es que, tras una representación de la amenaza como "difusa" y "trasnacional", ellas hacen del término "terrorista" un "peligro" funcional a la gubernamentalidad (Foucault, 2008) militarizada (o seguritizada). En ese esquema, -como señala Calveiro (2012)es sobre todo hacia el 2001 que se instala mundialmente la idea de una "guerra contra el terrorismo".

La noción de terrorista no sólo justifica la gestión represiva y/o militar de la conflictividad social, sino también la militarización del conjunto de las relaciones sociales de una determinada sociedad nacional estatalizada. Entenderla como dispositivo biopolítico permite observar cómo ella funciona como nodo de conexión de prácticas de gobierno y regímenes de verdad (Foucault, 2008). Pues, estamos ante formas de ejercicio del poder que se orientan a construir discursivamente una idea de terrorista sobre la cual operar pero que con ello abren un amplio campo de acción gubernamental, política, policial y militar.

Dicho esto, resulta particularmente interesante observar la manera en que ingresa la indigeneidad en ese campo de producción gubernamental. Pues, la transformación de la indigeneidad en foco de seguritización da lugar a nuevas formaciones nacionales de alteridad (Briones, 2008) (44) sobre las cuales ésta se apoya. Ella produce una serie de desplazamientos discursivos en los que la idea de "indígena" está siendo reinventada e inscripta en nuevas estrategias de gubernamentalidad. Las lógicas gubernamentales de control social que se aproximan a los modelos de "guerra antiterrorista", "guerra contra el crimen organizado" y estado de excepción necesitan de la figura de "indio terrorista". Pero dicha figura funciona a contramano de la lógica integracionista imperante durante todo el siglo XX: la construcción hegemónica de aboriginalidad está virando cada vez más a una idea de indígena que ya no descansa tanto en las nociones de inferioridad, atraso, minoridad y minusvalidad (aun cuando ellas no sean abandonadas por completo); sino antes bien en nociones de astucia, peligrosidad y capacidad de agencia. 
Esto último es un aspecto de central importancia a la hora de comprender las nuevas matrices de aboriginalidad que están emergiendo y/o los desplazamientos en las formaciones nacionales de alteridad (Briones, 2008). Acaso esté funcionando un giro ideológico y discursivo en el cual la distinción indígena/no-indígena encuentre nuevos vectores de corte, nuevos procesos de otrerización y, consecuentemente, nuevos procesos de identificación.

\section{A modo de cierre}

Es mucho lo que queda por estudiar respecto de las lógicas de reorganización hegemónica de la política indigenista actualmente operantes en Argentina. En este artículo apenas he querido dejar planteado que esos cambios se vinculan con una lógica de seguritización de la indigeneidad y que, para comprenderlos, es conveniente ejercitar un contrapunto con las formas en que en Chile han están siendo administrados los conflictos etnoterritoriales. Creo que debe observarse detenidamente la manera en que -desde hace dos décadas- el Estado chileno ha intentado gobernar y cercenar la demanda política mapuche.

Desde mi punto de vista, las muertes de Santiago Maldonado y Jorge Nahuel y los discursos gubernamentales construidos en torno de esos hechos merecen ser entendidos a partir de su inserción en un esquema de política estatal indigenista que hace de la seguritización de la indigeneidad su principal eje de acción. También creo necesario observar que el acuerdo firmado en 2017 entre los gobiernos de Bachelet y Macri para "atacar" al "terrorismo" y al "narcotráfico" no sólo representa un hito en la adopción que el Estado argentino hace del modelo chileno de administración de los conflictos etnoterritoriales, sino que también expresa una articulación interestatal organizada en torno de la seguritización de la indigeneidad.

Por último, es importante remarcar cómo los medios de comunicación contribuyen a crear discursos deslegitimadores de las reivindicaciones de tierras y los derechos indígenas estatuidos; al tiempo que informes gubernamentales pretendidamente serios interpretan las alianzas y las solidaridades de ONGs y entidades indigenistas como mecanismos de asociación ilegal y "amenazas" al orden y la "seguridad nacional". A través del análisis intenté demostrar que la construcción de una idea de indígena como "peligroso" y "amenazante" del orden público se aparece como la práctica discursiva funcional a la suspensión de la norma, propia del Estado de excepción (Agamben, 2005). Pues, fundándose en ello, la apelación a legislaciones antiterroristas habilita a los Estados para controlar militarmente territorios y circulaciones, acallar las demandas y disciplinar las resistencias. En este sentido, tal vez 
podríamos pensar que, luego de que las décadas de 1980 y 1990 trajeron un claro avance en cuanto a derechos de los pueblos originarios, algunos Estados y sectores del capital hoy están necesitando construir representaciones sobre el "otro" indígena que faciliten la suspensión de todo derecho. La deconstrucción minuciosa de este nudo político, teórico e histórico excede sobremanera los límites de este trabajo. Bastará entonces con que quede establecido como hilo de ovillo del cual "tirar" en nuestros próximos trabajos.

\section{Notas}

(1) Como en otros trabajos, aquí retomo la distinción entre política indígena y política indigenista planteada por Diana Lenton (2010). La autora propone denominar como política indigenista "toda política de Estado referida a los que hoy llamamos Pueblos Originarios, independientemente de su contenido axiológico" y reservar, en cambio, la expresión política indígena para aquella "política de representación y [las] estrategias de participación y/o autonomización de las organizaciones de militancia y/o colectivos de pertenencia de los Pueblos Originarios" (Lenton, 2010: 3).

(2) Lof es la organización comunitaria y sociopolítica de la sociedad mapuche. Desde la cosmovisión occidental suele ser traducido bajo el término "comunidad".

(3) Es importante observar que tal avance se vincula con la suba de los precios de los commodities a partir de la especulación financiera que se ha montado sobre ellos (Sosa, 2017).

(4) Al respecto, ver https://www.youtube.com/watch?v=jvi-yP1Xm5k

(5) https://bit.ly/2tTp000

(6) Es preciso observar que la condición federal de Argentina complejiza las posibilidades de una tal programación nacional de un modo que no ocurre en Chile.

(7) El término fue acuñado por Ole Waever (1995, citado en Treviño Rangel, 2016) para reflejar el proceso por el cual diversos sujetos (gobiernos, prensa, etcétera) orientan sus acciones hacia la construcción de una "amenaza" a la seguridad (nacional, interna, etcétera); la cual habilita entonces la apelación a medidas de emergencia, el fortalecimiento de ciertos dispositivos seguritarios y el despliegue de otros nuevos.

(8) Pairican, F. Rebelión en Wallmapu. Antecedentes del levantamiento indígena en el Chile actual. Le Monde Diplomatique, noviembre de 2012, p. 4.

(9) En 1996 surgió la Coordinadora Territorial Lafquenche. Se dividió a mediados de 1998 por desacuerdos respecto de la utilización o no de la violencia política como forma de lucha. En virtud de ese desprendimiento se organizó la Coordinadora Arauco Malleco, inclinada hacia la primera postura.

(10) Las "recuperaciones de tierras" alcanzaron una importante repercusión en la agenda mediática. Se insertaron en un imaginario que recordaba los conflictos territoriales que en los años setenta impulsó el pueblo mapuche en el marco de los procesos de reforma agraria y, en virtud de ello, alarmaron a los propietarios latifundistas.

(11) Revista del CESIM. Editorial, 4(3), julio-agosto 1999, p. 2.

(12) Revista del CESIM. El conflicto mapuche y su impacto en la seguridad nacional, 4(3), julio-agosto 1999, p. 20.

(13) Revista del CESIM. El conflicto mapuche y su impacto en la seguridad nacional, 4(3), julio-agosto 1999, p. 2.

(14) El Comité de Defensa de los Predios (CDP) surgió en 1999, sentando un primer y preocupante antecedente de la formación de fuerzas parapoliciales en la región de la Araucanía. Tres años más tarde, en 2002, un grupo de 
latifundistas -aún más enfático en su voluntad de "defender" la propiedad privada aún a costa de sangre- articuló el Comando Hernán Trizano. En forma provocativa y haciendo gala de una clara impronta genocida, el comando recuperaba así el nombre de quien fuera creador de las guardias civiles durante la eufemísticamente llamada "Pacificación de la Araucanía" (1881-1883).

(15) Aunque en este artículo nos limitamos a estudiar la dimensión judicial y represiva de la política indigenista estatal, es importante retener que el Gobierno de Ricardo Lagos mostró una doble cara en su política indigenista. Así, al compás de la criminalización de la protesta social mapuche, el gobierno emprendió programas sociales de promoción comunitaria, como el Programa Orígenes -iniciado en 2001 y financiado por el Banco Interamericano de Desarrollo(Bello, 2007) e impulsó la creación de la Comisión de Verdad Histórica y Nuevo Trato -cuyo Informe final reconoció la prexistencia de los pueblos originarios y se pronunció en favor de reformas institucionales que fortalecieran derechos colectivos indígenas (Aylwin, 2007).

(16) El 21 de agosto de 2004 el subsecretario del Interior del Gobierno de Ricardo Lagos, Jorge Correa Sutil, afirmó públicamente que la desarticulación de la Coordinadora Arauco Malleco había sido el resultado de una labor de inteligencia policial programada y llevada a cabo en forma sistemática desde el año 2000 (Pairican y Álvarez, 2011).

(17) Por caso vale señalar que, hasta la entrada en vigencia de la Ley de Inteligencia (2 de noviembre de 2004), las investigaciones hechas por el Estado sobre el movimiento mapuche carecieron de todo marco legal que las regule y limite. Una vez aprobada la ley, las escuchas sin permiso judicial pasaron tener amparo jurídico.

(18) Revista del CESIM. Editorial, 7(2), mayo-junio de 2002, p. 1.

(19) Alex Lemun agonizó durante cinco días y falleció el 12 de noviembre producto de un impacto de bala en su cráneo, efectuado por el carabinero Marco Aurelio Treuer. Al respecto, consultar el Documental Wiño Choyü tui Lemun: Lemun Renace https://www.youtube.com/watch?v=kK4PWtgxjY8 y https://www.youtube.com/watch?v=3halaWH0s5o

(20) Pairican, F. Rutas mapuche hacia la autodeterminación. La historia reciente de las luchas en La Araucanía. Le Monde Diplomatique, marzo de 2013, p. 8.

(21) APDH Regional Formosa. "Estado de situación en Ingeniero Juárez, desde la percepción de la sociedad civil", mayo de 2017, p. 7.

(22) APDH Regional Formosa. "Estado de situación en Ingeniero Juárez, desde la percepción de la sociedad civil", mayo de 2017, pp. 5-6.

(23) Como señala Diego Escolar (2017), desde finales de la década del noventa en adelante la Gendarmería ha sido una fuerza militar que cada vez más asumió funciones de seguridad interior.

(24) APDH Regional Formosa. "Estado de situación en Ingeniero Juárez, desde la percepción de la sociedad civil", mayo de 2017, p. 8.

(25) https://bit.ly/2tTp40y

En los tiempos en que este texto ingresa a edición, el presidente de la Nación hizo alarmantes declaraciones en favor de que las Fuerzas Armadas intervengan en asuntos de seguridad interior, lo cual es violatorio de la normativa vigente al respecto (ver https://bit.ly/2IYi2Ck).

(26) https://bit.ly/2IG2Uo6

(27) https://bit.ly/2MDjCXz (itálicas mías).

(28) Ver https://bit.ly/2IMjU2Y

(29) https://bit.ly/2Kk0xg9

(30) https://bit.ly/2KEgmxT

(31) Luego de la reunión, "ambos países emitieron un comunicado en el que destacaron cuatro puntos que fueron los ejes principales de la reunión: Conformar una comisión mixta de trabajo para abordar los aspectos operativos vinculados a la visita del Papa Francisco a Chile; coordinar el trabajo para abordar juntos emergencias por desastres 
Miguel Leone. Seguritización de la indigeneidad. La actual política indigenista de Argentina y Chile

naturales y otros; ejecutar -desde el mes de octubre- un plan conjunto de cierres de pasos fronterizos no habilitados en la zona sur, y activar el sistema para la cooperación en materia judicial respecto de antecedentes vinculados a hechos delictivos" (El Mercurio, 30 de septiembre de 2017, p. 12. En https://bit.ly/2tHsxA2) Fuente: Emol.com https://bit.ly/2tFRzzo

(32) En este plano, resulta paradigmático el caso Facundo Jones Huala -a quien el gobierno argentino acusa de ser el líder de la RAM (https://www.argentina.gob.ar/noticias/comando-unificado-contra-la-violencia-de-la-ram). En 2013 el poder judicial chileno abrió una causa contra Facundo Jones Huala y otros cinco mapuche acusándolos por el incendio de un campo cercano a Temuco. Todos fueron desprocesados, excepto Jones Huala. En octubre de 2016 el juez federal de Esquel (Argentina), Guido Otranto, inició un juicio de extradición en su contra. Sin embargo, el mismo fue anulado tras la constatación de torturas efectuadas sobre uno de los testigos en la causa. Ignorando el principio de non bis in idem, el juez federal Gustavo Villanueva hizo caso omiso de esa sentencia y emitió una nueva orden de detención sobre Jones Huala. Contó con el aval de la Corte Suprema de Justicia que estableció la nulidad del primer juicio y habilitó el inicio de un nuevo juicio. En julio de 2017 Jones Huala fue detenido y el 5 de febrero de 2018 fue dictada una nueva sentencia judicial que ordenó su extradición, tan ansiada por los poderes judicial, político y económico de Chile.

(33) El Mercurio, 30 de septiembre de 2017, p. 12. En https://bit.ly/2tHsxA2.

(34) El Convenio 169 de la OIT, establece, en su Parte VII (Sobre Contactos y Cooperación a Través de las Fronteras), artículo 32: "Los gobiernos deberán tomar medidas apropiadas, incluso por medio de acuerdos internacionales, para facilitar los contactos y la cooperación entre pueblos indígenas y tribales a través de las fronteras, incluidas las actividades en las esferas económica, social, cultural espiritual y del medio ambiente".

(35) La Declaración de las Naciones Unidas sobre los Derechos de los Pueblos Indígenas establece en su artículo 36: "Los pueblos indígenas, en particular los que están divididos por fronteras internacionales, tienen derecho a mantener y desarrollar los contactos, las relaciones y la cooperación, incluidas las actividades de carácter espiritual, cultural, político, económico y social, con sus propios miembros, así como con otros pueblos, a través de las fronteras". También plantea que "los Estados, en consulta y cooperación con los pueblos indígenas, adoptarán medidas eficaces para facilitar el ejercicio y asegurar la aplicación de este derecho".

(36) El 5 de enero de 2018 la Ministra de Seguridad afirmó que "el contacto con Chile es permanente" (https://bit.ly/2MAvitX).

(37) https://bit.ly/2Kp6qZq

(38) https://bit.ly/2Kpgx0J

(39) https://bit.ly/2Kk0xg9

(40) Espacio Nacional por la Paz y el Dialogo Intercultural. 3 de enero de 2018, "Comando Unificado contra la violencia de la RAM: La nueva embestida del Estado Nacional y provincial contra el pueblo mapuche”. En https://bit.ly/2KyklpT

(41) El "caso Luchsinger-Mackay" es probablemente el más cercano a la caracterización de "desprecio de la vida humana". El 4 de enero de 2013, el matrimonio Bernard Luchsinger y Vivianne Mackay, terratenientes de la región de Vilcún, murieron atrapados por las llamas cuando el casco de estancia en donde moraban fue prendido fuego por encapuchados -presumiblemente- activistas mapuche, en el marco de la conmemoración del quinto aniversario del asesinato de Matías Catrileo. En 2014, el machi Celestino Córdova fue condenado como autor del hecho. No obstante, no se probó la intención asesina ni el carácter terrorista del hecho. A pesar de que se realizó un segundo juicio, éste tampoco implicó la reversión de esa sentencia. Aun así, en el marco de una evidente persecución político-judicial sobre el movimiento mapuche, en 2018 fue iniciado un tercer y célere juicio. Esta vez sí la acción fue caracterizada como terrorista y lo cuestionable de los elementos probatorios no fue óbice para que otros dos mapuche (Luis y José Tralcal) fueran condenados por el mismo hecho.

Question, Vol. 1, N.o 59, julio-septiembre 2018. ISSN 1669-6581

Instituto de Investigaciones en Comunicación | Facultad de Periodismo y Comunicación Social | Universidad Nacional de

La Plata | La Plata | Buenos Aires | Argentina

Página 22 de 25 
(42) Es un caso paradigmático en ello el de Raúl Castro Antipán, infiltrado por Carabineros en las comunidades de La Araucanía, cuyas declaraciones permitieron enjuiciar y condenar a varios referentes mapuches.

(43) De acuerdo a declaraciones del subsecretario del Interior realizadas en 2005, el empleo de la Ley 18314 habría obedecido a las ventajas procesales que otorga a la parte acusadora para la investigación y construcción de pruebas, entre ellas el uso de testigos sin rostro.

(44) El concepto de formación nacional de alteridad es útil para entender ordenamientos complejos en los que las jerarquías de género, clase, geografía, raza y etnicidad, entre otros, se combinan para dar lugar a categorías sociales que habilitan e imposibilitan lugares de enunciación, producen y reproducen la estructura social, y tienen la capacidad de variar a lo largo del tiempo, modificando con ello los procesos de marcación e identificación social. Las formaciones nacionales de alteridad no sólo producen categorías y criterios de identificación y clasificación, sino también -con ellocondiciones asimétricas de existencia material atadas a marcaciones diferenciales de "otredad interna" (Briones, 2008).

\section{Bibliografía}

Agamben, G. (2005). Estado de excepción. Buenos Aires: Adriana Hidalgo editora.

Anzelini, L. (2017). El gobierno de Macri y la re-militarización de la seguridad pública 20152017: algunos apuntes para la discusión. Universidad Metropolitana para la Educación y el Trabajo: Buenos Aires.

Aylwin, J. (2007). La Política del "Nuevo Trato": antecedentes, alcances y limitaciones. En Yanes, N. y Aylwin, J. (eds.). El Gobierno de Lagos, los pueblos indígenas y el "nuevo trato" (pp. 29-58). Santiago: LOM ediciones.

Bello, Á. (2007). El Programa Orígenes y la política pública del gobierno de Lagos hacia los pueblos indígenas. En Yanes, N. y Aylwin, J. (eds.). El Gobierno de Lagos, los pueblos indígenas y el "nuevo trato" (pp. 193-220). Santiago: LOM ediciones.

Bourdieu, P. (1993). Esprits d'Etat. Genèse et structure du champ bureaucratique. Actes de la Recherche en Sciences Sociales, 96-97, mars, pp. 49-62.

Briones, C. (2008). Formaciones de alteridad: contextos globales, procesos nacionales y provinciales. En Briones, C. (Comp.). Cartografías Argentinas. Políticas indigenistas y formaciones provinciales de alteridad (pp. 9-36). Buenos Aires: Antropofagia.

Calveiro, P. (2012). Violencias de Estado. La guerra antiterrorista y la guerra contra el crimen como medios de control global. Argentina: Siglo XXI.

Ceceña, A. E. (2006). Los paradigmas de la militarización en América Latina. América Latina en movimiento. Recuperado de https://www.alainet.org/es/active/10216

Carrasco, M. (2000). Los derechos de los pueblos indígenas en Argentina. Buenos Aires: IWGIA/LHAKA HONHAT. 
de la Cadena, M. y Starn, O. (2009). Indigeneidad: problemáticas, experiencias y agendas en el nuevo milenio. Tabula Rasa, 10, enero-junio, 191-223.

Escolar, D. (2017). Gendarmería. Los límites de la obediencia. Buenos Aires: Editorial San Benito.

Figueroa Cerda, C. (s/f). La Inteligencia de Carabineros de Chile en la Araucanía (2000-2006) ¿Continuación del enemigo interno de la Doctrina de Seguridad Nacional o una nueva construcción de la amenaza? Recuperado de http://docplayer.es/45453910-Carolinafigueroa-cerda.html\#

Foucault, M. (2002). Vigilar y castigar: nacimiento de la prisión. Buenos Aires: Siglo XXI Editores.

Foucault, M. (2008). Nacimiento de la biopolítica: curso en el Còllege de France: 1978-1979, Buenos Aires: Fondo de Cultura Económica.

GELIND (Grupo de Estudios en Legislación Indígena) (2000). La producción legislativa entre 1984 y 1993. En Carrasco, M. Los derechos de los pueblos indígenas en Argentina (pp. 63-190). Buenos Aires: IGWIA-LLAKA HONHAT, Vinciguerra.

González, K.; Mella, E. y Lillo, R. (2007). La política de criminalización del Movimiento mapuche bajo el sexenio de Lagos. En Yanes, N. y Aylwin, J. (eds.). El Gobierno de Lagos, los pueblos indígenas y el "nuevo trato" (pp. 59-99). Santiago: LOM ediciones.

Hocsman, L. D. (2014). Tierra, capital y producción agroalimentaria: despojo y resistencias en Argentina. En Almeyra, G.; Concheiro Bórquez, L.; Mendes Pereira, J. M. y PortoGonçalves, C. W. (coords). Capitalismo: Tierra y poder en América latina (1982-2012). Argentina, Brasil, Chile, Paraguay, Uruguay (Volumen I), (pp. 17-62). Buenos Aires: Consejo Latinoamericano de Ciencias Sociales.

Lenton, D. (2010). Política indigenista argentina. Una construcción inconclusa. Anuário Antropológico, l, Rio de Janeiro, 57-97.

Lenton, D. y Lorenzetti, M. (2005). Neoindigenismo de necesidad y urgencia: la inclusión de los Pueblos Indígenas en la agenda del Estado neoasistencialista. En Briones, C. (Comp.). Cartografías Argentinas. Políticas indigenistas y formaciones provinciales de alteridad (pp. 243-270). Buenos Aires: Antropofagia.

Leone, M. (1 de noviembre de 2016). Prácticas de pastoral aborigen y juridización de derechos indígenas en Argentina. Un análisis de la región del Chaco (1965-1994). (Tesis de doctorado). Universidad Nacional de General Sarmiento-Instituto de Desarrollo Económico y Social, Los Polvorines, Buenos Aires. 
Marimán, J. A. (1994). Transición democrática en Chile ¿Nuevo ciclo reivindicativo mapuche? Caravelle: Cahiers du Monde Hispanique et Luso- Bresilien, 63, 91-118. Recuperado de http://www.persee.fr/doc/carav_1147-6753_1994_num_63_1_2609

Mella Seguel, E. (2007). Los mapuche ante la justicia. La criminalización de la protesta indígena en Chile. Santiago: LOM ediciones.

Pairicán, F. y Álvarez, R. (agosto de 2011). La Nueva Guerra de Arauco: La Coordinadora Arauco Malleco en el Chile de la Concertación de Partidos por la Democracia (19972009). Revista Izquierdas, 10, 66-84.

Pinto Rodríguez, J. (2017). Estados en crisis, agudización de los conflictos étnicos-sociales en América latina, 1980-2016. Quinto Sol, 21(3), pp. 1-8. doi: http://dx.doi.org/10.19137/qs.v21i3.2112

Sosa, A. P. (2017). El papel de las megaempresas agropecuarias en la financiarización del régimen alimentario global. Los casos del Grupo Los Grobo y El Tejar en Argentina y en Brasil (1996-2015). (Tesis de Doctorado). Facultad de Ciencias Sociales, Universidad de Buenos Aires (UBA)-École Doctorale TESC, Université de Toulouse 2Jean Jaurès (UT2J).

Toledo Llancaqueo, V. (septiembre de 2007). Prima ratio. Movilización mapuche y política penal. Los marcos de la política indígena en Chile 1990-2007. OSAL, VIII(22), CLACSO, Buenos Aires, pp. 253-293.

Treviño Rangel, J. (2016). ¿De qué hablamos cuando hablamos de la "securitización" de la migración internacional en México?: una crítica. Foro Internacional 224, LVI(2), 253291. 